VESTIBOLOGY

\title{
Vertigo returning to the sitting position after the Semont manoeuvre. Is it a prognostic symptom?
}

\section{La comparsa di vertigine al ritorno nella posizione seduta della manovra di Semont può esser considerata un fattore prognostico?}

\author{
A. ALBERA 1 , M. BOLDREGHINI², A. CANALE², R. ALBERA², C.F. GERVASIO² \\ 1 Department of Otolaryngology, San Giuseppe Hospital, University of Milan, Italy; ${ }^{2}$ Department of Surgical \\ Sciences, Otolaryngology Unit, University of Turin, Italy
}

\section{SUMMARY}

Benign paroxysmal positional vertigo (BPPV) is a frequent benign vestibular condition usually managed with particle repositioning manoeuvres, such as Semont manoeuvre (SM). Since few authors have described prognostic aspects of liberatory manoeuvres, the purpose of the present study was to investigate the possibility of considering vertigo in the final sitting position of the SM as a prognostic symptom in the outcome of posterior BPPV. One hundred and thirteen patients with diagnosis of unilateral posterior BPPV were taking into account in our retrospective cohort study: 41 men and 72 women, aged 22 to 85 years. All were submitted to one repositioning SM and afterwards controlled 3 to 5 days later by means of an additional Dix-Hallpike manoeuvre. The main outcomes investigated were the occurrence of Ny and vertigo in the different phases of the $\mathrm{SM}$, as well as their characteristics in relation to outcome of the disease. Among all patients, $75(66 \%)$ presented both orthotropic Ny and vertigo in the second SM position and $72 \%$ obtained a complete resolution of the disease after the liberatory manoeuvre. Contrarily, 17 subjects (15\%) manifested vertigo in the final sitting position of the SM and among these, only 7 (41\%) completely recovered from BPPV. According to our data, in case of sudden vertigo returning to the final sitting position of the SM, the failure rate of the liberatory manoeuvre was higher, even though not statistically significant: therefore, it can be considered as a negative prognostic factor of posterior BPPV after SM.

KEY WORDS: BPPV • Semont manoeuvre $\bullet$ Semont prognostic factors $\bullet$ BPPV outcomes $\bullet$ Positional vertigo

\section{RIASSUNTO}

La vertigine parossistica posizionale benigna $(B P P V)$ è la patologia che più frequentemente colpisce il labirinto e si manifesta con crisi di vertigine parossistiche, ovvero intense e di breve durata. Poiché la BPPV, provocata da un disturbo meccanico dell'organo dell'equilibrio, è considerata una patologia ad andamento benigno, viene normalmente gestita con manovre di riposizionamento degli otoliti chiamate manovre liberatorie: tra queste vi è la manovra di Semont (SM). L'obiettivo del presente studio è indagare se vi sia la possibilità di considerare la vertigine che talvolta insorge al ritorno nella posizione seduta finale della SM come un fattore prognostico riguardo l'esito della manovra stessa e quindi la risoluzione della patologia. Sono stati presi in considerazione per questo studio retrospettivo 113 pazienti con diagnosi di BPPV unilaterale posteriore: 41 uomini e 72 donne, di età compresa tra 22 e 85 anni. Tutti sono stati sottoposti a una SM liberatoria e in seguito controllati dopo 3-5 giorni mediante una nuova manovra Dix-Hallpike diagnostica. Tra le diverse variabili indagate, il principale dato preso in considerazione è stato il verificarsi di nistagmo (Ny) elo vertigine nelle diverse posizioni della SM, nonché le loro caratteristiche in funzione dell'evoluzione della malattia. Tra tutti i campioni, 75 pazienti (66\%) presentavano sia vertigine che Ny nella seconda posizione della SM ed il $72 \%$ di essi ha ottenuto una completa risoluzione della malattia dopo tale manovra liberatoria. Al contrario, 17 soggetti (15\%) hanno manifestato esclusivamente vertigini al ritorno nella posizione seduta finale della SM e tra di essi solo 7 pazienti (41\%) hanno ottenuto una completa remissione della BPPV. Secondo i dati in nostro possesso si può pertanto affermare che, in caso di insorgenza di vertigini nella posizione seduta finale della SM, il tasso di fallimento della manovra liberatoria è risultato molto più elevato, anche se non statisticamente significativo: tale risultato può essere considerato un fattore prognostico negativo nell'outcome della BPPV posteriore dopo SM.

PAROLE CHIAVE: BPPV • Manovra di Semont $\bullet$ Fattori prognostici della BPPV $\bullet$ Esiti di BPPV $\bullet$ Vertigine posizionale

Acta Otorhinolaryngol Ital 2018;38:145-150

\section{Introduction}

Benign paroxysmal positional vertigo (BPPV) is the most frequent vestibular disorder ${ }^{12}$ and is characterised by recurrent acute vertigo episodes triggered by changes in head position in everyday activities, commonly when rolling over in bed, bending forward or tilting the head to 
look upward. The disease was first described by Bárány in 1921 as a disorder of the otolithic organ and was afterwards named by Dix and Hallpike in $1952^{3}$. Canalithiasis is recognised as the most widely accepted theory in the pathogenesis of the disease: according to this theory, freefloating otoliths move along the concerned semicircular canal under the influence of gravity when changing the head position along the earth-vertical plane. These displacements induce a hydrodynamic endolymphatic flow which induces a deflection of the cupola, leading to the onset of acute vertigo and nystagmus $(\mathrm{Ny})$ by changing the firing rate of the vestibular nerve ${ }^{45}$.

A population-based study estimated that BPPV has a lifetime prevalence of $2.4 \%$ and accounts for $8 \%$ of individuals with moderate to severe dizziness or vertigo ${ }^{6}$.

In 60-90\% of cases, BPPV affects the posterior semicircular canal; the lateral semicircular canal is only occasionally involved whereas the superior semicircular canal is rarely indicated as the cause of the disorder ${ }^{7}$.

Liberatory manoeuvres are nowadays considered the gold standard in the treatment of BPPV, inducing short term resolution of vertigo in more than $70 \%$ of cases and an overall success rate of $90 \%$ after carrying out four different manoeuvres ${ }^{89}$. These manoeuvres are intended, employing stepwise changes in head position, to flush free-floating otolithic debris out of the most sensitive part of the inner ear to a less sensitive location, namely from the involved semicircular canal back to the utricle. In case of involvement of the posterior semicircular canal, Semont's (SM) and Epley's manoeuvres are considered the most effective therapeutic procedures ${ }^{1011}$, and nowadays the SM level of recommendation for treating BPPV is currently $\mathrm{B}^{8}$.

The main side effects after repositioning manoeuvres are the possible conversion from posterior to lateral semicircular canal BPPV and a postural persisting unsteadiness ${ }^{9}$. Immediate recurrence is rarely reported in literature, whereas long-term recurrence is described in about $50 \%$ of cases ${ }^{9}$. A typical immediate manifestation during repositioning manoeuvres such as SM is the occurrence of an orthotropic Ny beating in the same direction of the one recorded just after reaching the primary position (the rapidly obtained side-lying position to the affected side after the head is turned $45^{\circ}$ to the unaffected side). This sudden $\mathrm{Ny}$ is always associated with a paroxysmal vertigo and both come out as soon as the patient is forced by the physician to turn the head toward the healthy side (second position) ${ }^{2}$.

The occurrence of this Ny several seconds to minutes after reaching the second SM position, which is also described performing the Epley canalith repositioning procedure, is defined "liberatory Ny" and is considered as a positive predicting factor for the effectiveness of the previously ex- ecuted manoeuvre ${ }^{6712-14}$. In the absence of such orthotropic $\mathrm{Ny}$ soon after the second SM position, sometimes BPPV patients manifest an intense paroxysmal acute vertigo getting up to the final sitting position of the same manoeuvre, with the legs hanging off the edge of the examination table. The purpose of the present retrospective cohort study was to define whether the occurrence of acute vertigo returning to the final sitting position of SM could be considered a prognostic factor for the effectiveness of the liberatory manoeuvre itself.

\section{Materials and methods}

A cohort of 113 patients suffering from unilateral posterior semicircular canal BPPV were included in the present retrospective study after being investigated by our ENT tertiary referral centre at the University of Turin "Città della Salute" Hospital, over a three-year period (January $1^{\text {st }}, 2014$ - December $31^{\text {st }}, 2016$ ).

Posterior semicircular canal BPPV was diagnosed according to the American Academy of Otolaryngology Head and Neck Surgery Foundation guidelines ${ }^{15}$ : (a) history of vertigo associated with changes in head position; (b) characteristic mixed torsional-vertical nystagmus, with the upper pole of the eye beating toward the affected ear and the vertical component beating toward the forehead (clockwise geotropic nystagmus in left ear forms and counterclockwise geotropic nystagmus in right ear forms from the examiner point of view). Ny detected with Frenzel's glasses (optical or video) or videonystagmography in the Dix-Hallpike maneuver (DHM) that increases and resolves within 1 minute; (c) paroxysmal vertigo associated with the elicited nystagmus; (d) latency period between the completion of the DHM and the onset of rotational vertigo and the objective nystagmus.

Exclusion criteria were diagnosis of either lateral or anterior semicircular canal canalithiasis, bilateral forms of BPPV, presence of other middle and inner ear pathologies, previous liberatory manoeuvres carried out to treat the same episode of disease and persistence of positional vertigo in the 3-5 days between the appropriate repositioning manoeuvre and outpatient control visit.

Furthermore, patients who did not present both characteristic Ny and vertigo in the primary position of SM were excluded, whereas patients suffering from recurrent BPPV were admitted to the study.

We decided to evaluate the following parameters of the disease: mean duration of the last BPPV episode since the onset of symptomatology, number of previous crisis and vertigo intensity by a visual-analogue- scale ranging from 0 to 10 . 
Ten minutes after a positive DHM, patients were submitted to liberatory SM as follows: the patient is seated in the upright position on an examination table with the legs hanging down, then the head is turned $45^{\circ}$ toward the unaffected side and rapidly moved to the opposite side-lying position. The patient is held in this position until both vertigo and Ny disappear (approximately 30 seconds). Afterward the patient is suddenly turned $180^{\circ}$ toward the unaffected side-lying position, without pausing in the sitting position and without changing the head position relative to the shoulder (therefore at the end of this movement the head is turned down); the present position is maintained, like before, until both vertigo and $\mathrm{Ny}$ disappear or, in the absence of any manifestation, for at least 2 minutes. Finally, the patient is gently raised up to the first seated position, eventually reporting the occurrence of either orthotropic Ny or vertigo.

All patients admitted to the study were afterwards controlled 3 to 5 days later in the outpatient and submitted again to a DHM; in case of positivity of the DHM, we evaluated the intensity of the reported vertigo and the relative Ny, comparing them to the baseline control.

Written informed consent to be routinely submitted to the tests was obtained by each of the enrolled subjects. The study was carried out according to the 1964 Helsinki Declaration and its later amendments or comparable ethical standards; nevertheless, in all cases we performed the common diagnostic and therapeutic procedures usually carried out to pursuit the resolving BPPV.

Statistical analysis of the data was performed using SPSS software ver. 23 (Chicago, IL, USA). A KolmogorovSmirnov test was used to test the normality of the distribution among the different groups of patients enrolled in this study. Since the Kolmogorov-Smirnov test demonstrated a normal distribution among all the different groups of patients, the parametric test of Chi-square (for categorical variables) and Student's T test (for continuous variables) were used when appropriate. A level of significance of 0.05 was set for all tests.

\section{Results}

Among all the 113 patients suffering from posterior semicircular canal BPPV enrolled in the present study, 72 subjects (64\%) were females and 41 subjects $(36 \%)$ were males, while the mean age of the group resulted $62.6 \pm 12$ years (range 22-85). The right ear was affected in 70 cases $(62 \%)$ whereas the left ear was involved in 43 patients $(38 \%)$. A certain aetiology was identifiable in only 10 cases (9\%) and among these trauma in 7 cases (6\%) and vestibular neuritis in 3 patients (3\%).
The BPPV episodes investigated presented an average duration of $41 \pm 53$ days since the occurrence of positional symptomatology and the mean value at the visualanalogue scale was 5 of 10 (range 1-9). The reported average number of similar previously experienced episodes was 2.2 (range 0 to 15 ), whereas 58 patients (51\%) were observed during their first episode of vertigo.

Among all subjects, 75 patients $(66 \%)$ presented both orthotropic Ny and vertigo in the second position of SM, 17 subjects $(15 \%)$ manifested vertigo returning to the final SM sitting position and 21 patients $(19 \%)$ demonstrated neither objective Ny nor vertigo in either the second or final SM sitting positions.

None of the patients reported vertigo getting up to the last sitting position after having had orthotropic Ny in both the first and in the second face down SM positions. Differently, in case of vertigo returning to the sitting position, we detected (47\%) the development of Ny beating in the opposite direction respect to the one recorded in the primary SM position in 8 cases.

Age at diagnosis, duration of the BPPV episode since the onset of symptomatology, overall number of crisis and vertigo intensity did not differ significantly $(p>0.05)$ at the ANOVA test in relation to the occurrence of clinical signs such as orthotropic $\mathrm{Ny}$ or to the onset of subjective symptoms like vertigo during the SM (Table I). Similarly, even the gender of patients and evidence of a well-known cause for BPPV did not significantly conditioned the response to $\mathrm{SM}$ ( $\mathrm{p}>0.05$ by Chi-Square test).

Performing the outpatient control visit at 3 to 5 days after the first SM by additional diagnostic DHM, 70 patients (62\%) manifested a complete resolution of the disease, 24 subjects $(21 \%)$ reported a stable persistence of symptomatology, with objective $\mathrm{Ny}$ and vertigo, and 19 patients (17\%) demonstrated a moderate improvement of the disease, characterised by a less intense vertigo and evidence of a lower intensity of orthotropic $\mathrm{Ny}$.

Similar to the previous results, age of the patients, duration of the BPPV episode since the onset of symptomatology, overall number of crisis and vertigo intensity did not differ significantly $(p>0.05)$ at the ANOVA test even in relation to the outcome of the disease 3 to 5 days after the SM (Table II), despite an evident shorter mean duration of the BPPV episode.

The prevalence of the final outcome of the liberatory manoeuvre, classified as complete resolution of BPPV, moderate improvement of the disease and stable persistence of disease, in relation to the clinical signs and symptoms after SM as reported in Table III. Differences at Chi-Square test were not significant $(p>0.05)$, although there was a higher probability of obtaining a complete resolution in 
Table I. Age at diagnosis, last episode duration since the onset of symptomatology, overall number of crisis and vertigo intensity in relation to the clinical manifestations occurred performing SM due to posterior BPPV. Differences not significant by ANOVA test ( $p>0.05)$.

\begin{tabular}{|c|c|c|c|c|}
\hline & $\begin{array}{l}\text { Age } \\
\text { (a) }\end{array}$ & $\begin{array}{l}\text { Last episode } \\
\text { duration (b) }\end{array}$ & $\begin{array}{l}\text { Overall number } \\
\text { of crisis }\end{array}$ & $\begin{array}{l}\text { Vertigo intensity } \\
\text { (c) }\end{array}$ \\
\hline $\begin{array}{l}\text { No clinical manifestations } \\
(\mathrm{n}=21)\end{array}$ & $61 \pm 14$ & $45 \pm 48$ & $2.7 \pm 2.8$ & $4.8 \pm 2.1$ \\
\hline Both orthotropic Ny and vertigo in the second SM position $(n=75)$ & $63 \pm 11$ & $43 \pm 59$ & $2.1 \pm 2.1$ & $5.1 \pm 1.3$ \\
\hline Vertigo returning to sitting position $(\mathrm{n}=17)$ & $62 \pm 11$ & $29 \pm 27$ & $1.9 \pm 2.2$ & $5.1 \pm 1.7$ \\
\hline $\mathrm{p}$ & $>0.05$ & $>0.05$ & $>0.05$ & $>0.05$ \\
\hline
\end{tabular}

a: age is expressed in years; $b$ : last episode duration is expressed in days; $c$ : vertigo intensity values are expressed out of 10 at the visual-analogue-scale.

Table II. Age at diagnosis, last episode duration since the onset of symptomatology, overall number of crisis and vertigo intensity in relation to the final outcome of a single SM performed due to posterior BPPV. Differences resulted not significant at the ANOVA test ( $p>0.05)$.

\begin{tabular}{|c|c|c|c|c|}
\hline & $\begin{array}{l}\text { Age } \\
\text { (a) }\end{array}$ & $\begin{array}{l}\text { Last episode } \\
\text { duration (b) }\end{array}$ & $\begin{array}{l}\text { Overall number } \\
\text { of crisis }\end{array}$ & $\begin{array}{l}\text { Vertigo intensity } \\
\text { (c) }\end{array}$ \\
\hline Persistence of disease $(n=24)$ & $65 \pm 9$ & $24 \pm 26$ & $2.2 \pm 2.3$ & $5.4 \pm 1.2$ \\
\hline $\begin{array}{l}\text { Moderate improvement } \\
(\mathrm{n}=19)\end{array}$ & $62 \pm 11$ & $43 \pm 34$ & $3 \pm 3.3$ & $4.8 \pm 1.6$ \\
\hline $\begin{array}{l}\text { Complete resolution } \\
(\mathrm{n}=70)\end{array}$ & $62 \pm 14$ & $46 \pm 62$ & $2 \pm 1.9$ & $5 \pm 1.6$ \\
\hline $\mathrm{p}$ & $>0.05$ & $>0.05$ & $>0.05$ & $>0.05$ \\
\hline
\end{tabular}

a: age values are expressed in years; b: last episode duration is expressed in days.; c: vertigo intensity values are expressed out of 10 at the visual-analogue-scale.

Table III. Final outcome of a single SM due to posterior BPPV in relation to the clinical manifestations occurred performing the manoeuvre itself. Differences resulted not significant at Chi-Square test $(p>0.05)$.

\begin{tabular}{lccc} 
& $\begin{array}{c}\text { No clinical } \\
\text { manifestations }\end{array}$ & $\begin{array}{c}\text { Both orthotropic Ny and vertigo } \\
\text { in the second SM position }\end{array}$ & $\begin{array}{c}\text { Vertigo returning } \\
\text { to sitting position }\end{array}$ \\
Persistence of disease $(n=24)$ & $4(17 \%)$ & $14(58 \%)$ & $6(25 \%)$ \\
Moderate improvement $(n=19)$ & $7(37 \%)$ & $8(42 \%)$ & $4(21 \%)$ \\
Complete resolution $(n=70)$ & $10(14 \%)$ & $53(76 \%)$ & $7(10 \%)$ \\
\hline
\end{tabular}

case of onset of both objective orthotropic Ny and vertigo during the second SM position; furthermore, among patients who reported an intense vertigo returning to final sitting SM position, there was a higher prevalence of stable persistence of disease 3 to 5 days after performing the manoeuvre, even though such difference was not significant ( $\mathrm{p}>0.05)$.

\section{Discussion}

Particle repositioning manoeuvres by Epley and Semont ${ }^{911}$ are nowadays considered the gold standard in BPPV therapy due to posterior semicircular canal canalithiasis, with a success rate after the first manoeuvre ranging from 50 to $90 \% 78121617$.

A typical prompt reaction after liberatory manoeuvres is the sudden onset of an orthotropic Ny coupled with an objective vertigo, which comes out getting the second po- sition of the SM, namely the stance with the head turned toward the unaffected ear.

This occurrence is commonly considered as a positive prognostic sign with respect to the efficacy of the manoeuvre itself 781214 , since it should confirm the exit of otoconial debris from the posterior semicircular canal to the utricule; on the other hand, the absence of such typical orthotropic Ny might suggest that the manoeuvre did not correctly displace the otoliths toward the utricle. In literature a $70 \%$ to $80 \%$ success rate of the SM is described in case of onset of an orthotropic $\mathrm{Ny}$ in the second position of the manoeuvre itself; contrarily, in the lack of any clinical objective signs, such value will drop to $50 \%{ }^{79}{ }^{14}$.

In the absence of both orthotropic Ny and vertigo soon after the second position of the liberatory manoeuvre, we frequently observed the onset of vertigo which manifests as soon as the patient gets in the final sitting position of the SM; such objective vertigo was sometimes so intense 
that the subject had to be strongly held by the examiner to avoid falling from the examination table. This aforementioned clinical manifestation has never been considered as a possible prognostic factor for the outcome of the liberatory manoeuvres.

In order to correlate the immediate events after SM with the outcome of the manoeuvre itself, in the present study it was decided to examine a group of patients affected by BPPV due to posterior canalithiasis and submitted to SM, the liberatory manoeuvre we use as first choice in our ENT department in these cases.

Our results demonstrated a complete resolution of vertigo in $62 \%$ of patients after the first SM; nevertheless, also taking into account subjects who reported a significant improvement of symptomatology, which is often considered sufficient to obtain a good quality of life while waiting for natural resolution of the disease, we have reached an overall $79 \%$ of positive results after the first treatment. The outcome of the SM was not correlated to gender, age of patients at diagnosis, overall number of crisis, or subjective vertigo intensity during the episodes ${ }^{18}$. Even the duration of the BPPV episode since the onset of symptomatology was not significantly different in relation with the outcome of the SM (persistence of disease, moderate improvement of disease and complete resolution).

Moreover, in concordance with previous studies 781216 , our data has highlighted the occurrence of both typical orthotropic Ny and vertigo in $66 \%$ of patients in the second position of the SM. Among the 38 patients who manifested neither orthotropic Ny nor vertigo in the second face down position of the SM, we observed the occurrence of an intense vertigo when returning to the final sitting position in 17 cases, namely $15 \%$ of the overall sample. Since the onset of vertigo induced by liberatory SM is considered probative of otoconial particle movements ${ }^{7}$, we can therefore suppose that SM led to otolith displacement in $81 \%$ of patients, although with different final outcomes.

According to our data, differences in the outcome did not result significantly correlate either with the presence or with the absence of any clinical manifestation in the second SM position, even if the rate of success was considerably higher in patients who manifested orthotropic Ny. Therefore, the present study supports our conviction that the onset of Ny during the second position of liberatory SM should not be interpreted as a certain positive prognostic factor for posterior canalithiasis, since even in the absence of orthotropic Ny we could not exclude in advance the probable resolution of the disease. For that reason, an outpatient vestibular control, including an additional DHM to check any persistence of BPPV after the first SM, should be always afterward scheduled, whatever the outcome of the manoeuvre ${ }^{7}$.

Among all patients submitted to SM due to posterior BP$\mathrm{PV}$, we reported a higher rate of complete resolution of the disease in case of occurrence of both orthotropic $\mathrm{Ny}$ and vertigo in the second SM position, as like as a higher persistence of disease was described in those subjects who manifested vertigo returning to the last sitting position. Therefore, the onset of such acute vertigo, evoked while getting up to the last sitting position soon after SM, could be considered as a negative prognostic sign in the outcome of posterior BPPV, highlighting a relatively higher failure rate of the liberatory manoeuvre.

The accurate examination of patients who experienced acute vertigo in the final sitting position of the SM allowed us to also detect a simultaneous $\mathrm{Ny}$ in $47 \%$ of cases; nevertheless, we cannot exclude that the aforementioned Ny could be evaluated every time at the end of the manoeuvre, although difficult to observe due to the intense postural imbalance evoked in these patients, which obliged us to firmly handle them to avoid any fall from the examination bed.

The direction of the Ny evoked in the last sitting position of the SM furthermore allows us to speculate about its genesis: since it has been reported to proceed in a direction opposite to the one evoked both by primary and secondary SM positions due to an ampullifugal movement of otoconia ${ }^{13}$, we can therefore suppose in this case that the otoliths displacement was directed toward the ampulla. As a result, the occurrence of this response to liberatory SM could demonstrate the persistence of otoconial debris within the semicircular canal, probably due to a more proximal position of such otoconia to the ampulla, leading to a protraction of the symptomatology and to a worse prognosis of the disease.

\section{Conclusions}

In conclusion, the possibility of identifying any prognostic criteria during or soon after the administration of a SM due to posterior BPPV might be useful to plan further controls or to suggest post-manoeuvre postural restrictions, even though they have been considered useless according to the AAO-HNS guidelines ${ }^{13}$. Our data, in agreement with the above-mentioned guidelines, suggest that the occurrence of an orthotropic Ny in the second SM position is a positive prognostic factor in the outcome of a posterior BPPV, although it cannot be considered as certainly probative of vertigo resolution. Contrarily, in case of vertigo returning to the final sitting SM position or otherwise in the absence of any clinical manifestations ( $\mathrm{Ny}$ 
and/or vertigo) after SM, the failure rate of the liberatory manoeuvre increases, so that these conditions can be considered as negative prognostic signs of posterior BPPV outcome.

\section{References}

1 Hotson JR, Baloh RW. Acute vestibular syndrome. N Engl J Med 1998;339:680-5.

2 Furman JM, Cass SP. Benign paroxysmal positional vertigo. N Engl J Med 1999;341:1590-6.

3 Dix MR, Hallpike CS. The pathology, symptomatology and diagnosis of certain common disorders of the vestibular system. Ann Otol Rhinol Laryngol 1952;61:987-1016.

4 Parnes LS, McClure JA. Free-floating endolymph particles: a new operative finding during posterior semicircular canal occlusion. Laryngoscope 1992;102:988-92.

5 Rajguru SM, Rabbitt RD. Afferent responses during experimentally induced semicircular canalithiasis. J Neurophysiol 2007;97:2355-63.

6 von Brevern M, Radtke A, Lezius F, et al. Epidemiology of benign paroxysmal positional vertigo: a population based study. J Neurol Neurosurg Psychiatry 2007;78:710-5.

7 Soto-Varela A, Rossi-Izquierdo M, Santos-Pérez S. Can we predict the efficacy of the semont maneuver in the treatment of benign paroxysmal positional vertigo of the posterior semicircular canal? Otol Neurotol 2011;32:1008-11.

8 Mandalà M, Santoro GP, Asprella Libonati GA, et al. Double-blind randomized trial on short-term efficacy of the Semont maneuver for the treatment of posterior canal benign paroxysmal position vertigo. J Neurol 2012;259:882-5.

9 Zhang X, Qian X, Lu L, et al. Effects of Semont maneuver on benign paroxysmal positional vertigo: a meta-analysis. Acta Otorhinol 2017;137:63-70.

10 Semont A, Freyss G, Vitte E. Curing the BPPV with a liberatory maneuver. Adv Otorhinolaryngol 1988;42:290-3.

11 Epley JM. The canalith repositioning procedure: for treatment of benign paroxysmal positional vertigo. Otolaryngol Head Neck Surg 1992;107:399-404.

12 Oh HJ, Kim JS, Han BI, et al. Predicting a successful treatment in posterior canal benign paroxysmal positional vertigo. Neurology 2007;68:1219-22.

13 Toupet M, Ferrary E, Bozorg Grayeli A. Effect of repositioning menuever type and postmaneuver restrictions on vertigo and dizziness in benign positional paroxysmal vertigo. ScientificWorldJournal 2012:162123.

14 Califano L, Capparuccia PG, Di Maria D, et al. Treatment of benign paroxysmal positional vertigo of posterior semicircular canal by "Quick Liberatory Rotation Manoeuvre". Acta Otorhinolaryngol Ital 2003;23:161-7.

15 Bhattacharyya N, Baugh RF, Orvidas L, et al. American Academy of Otolaryngology Head and Neck Surgery Foundation. Clinical practice guideline: benign paroxysmal positional vertigo. Otolaryngol Head Neck Surg 2008;139:S47-81.

16 Chen Y, Zhuang J, Zhang L, et al. Short-term efficacy of Semont maneuver for benign paroxysmal positional vertigo: a doubleblind randomized trial. Otol Neurotol 2012;33:1127-30.

17 Kahraman SS, Yildirim YS, Tugrul S, et al. Repositioning intervals in the modified Epley's maneuver and their effect on benign paroxysmal positional vertigo treatment outcome. Acta Otolaryngol 2017;137:490-4.

18 Babac S, Djeric D, Petrovic-Lazic M, et al. Why do treatment failure and recurrences of benign paroxysmal positional vertigo occur? Otology Neurotol 2014;35:1105-10. 